\title{
Coping Effectively with Heart Failure (COPE-HF): Design and Rationale of a Telephone-based Coping Skills Intervention
}

\author{
Andrew Sherwood, $\mathrm{PhD}^{1}$, Christopher M. O'Connor, $\mathrm{MD}^{1}$, Faye S. Routledge, RN, $\mathrm{PhD}^{1}$, \\ Alan L. Hinderliter, MD ${ }^{2}$, Lana L. Watkins, PhD $^{1}$, Michael A. Babyak, PhD ${ }^{1}$, Gary G. Koch, \\ $\mathrm{PhD}^{2}$, Kirkwood F. Adams Jr., MD², Carla Sueta Dupree, MD, PhD ${ }^{2}$, Patricia P. Chang, MD, \\ MHS $^{2}$, Benson M. Hoffman, PhD ${ }^{1}$, Julie Johnson, PA ${ }^{1}$, Margaret Bowers, NP ${ }^{1}$, Kristy S. \\ Johnson, $\mathbf{M P H}^{1}$, and James A. Blumenthal, $\mathbf{P h D}^{1}$ \\ ${ }^{1}$ Duke University Medical Center, Durham, NC, USA \\ ${ }^{2}$ University of North Carolina, Chapel Hill, NC, USA
}

\begin{abstract}
Background-Coping Effectively with Heart Failure (COPE-HF) is an ongoing randomized clinical trial funded by the National Institutes of Health to evaluate if a Coping Skills Training (CST) intervention will result in improved health status and quality of life as well as reduced mortality and hospitalizations compared to a Heart Failure Education (HFE) intervention.

Methods-Two hundred heart failure (HF) patients recruited from Duke University Medical Center and the University of North Carolina Hospital systems will be randomized to a CST intervention (16 weekly, 30 minute telephone counselling sessions including motivational interviewing and individually tailored cognitive behavioral therapy) or to an HFE intervention (16 weekly, 30 minute telephone sessions including education and symptom monitoring). Primary outcomes will include post-intervention effects on HF biomarkers (B-Type naturetic peptide, ejection fraction) and quality of life, as well as long-term clinical outcomes (hospitalizations and death). Secondary analyses will include an evaluation of treatment effects across subpopulations, and potential mechanisms by which CST may improve clinical outcomes.
\end{abstract}

Conclusions-COPE-HF is a proof-of-concept study that should provide important insights into the health benefits of a CST intervention designed to enhance HF self-management, improve health behaviors, and reduce psychological distress.

\section{Keywords}

Self-management; biomarkers; quality of life; depression

\footnotetext{
(C) 2010 Elsevier Inc. All rights reserved.

Corresponding Author: Andrew Sherwood, PhD, Box 3119, Department of Psychiatry and Behavioral Sciences, Duke University Medical Center, Durham, NC 27710, Tel: (919)-684-3828; Fax : (919) 684-8629; sherw002@ mc.duke.edu.

Disclosures None.

Publisher's Disclaimer: This is a PDF file of an unedited manuscript that has been accepted for publication. As a service to our customers we are providing this early version of the manuscript. The manuscript will undergo copyediting, typesetting, and review of the resulting proof before it is published in its final citable form. Please note that during the production process errors may be discovered which could affect the content, and all legal disclaimers that apply to the journal pertain.
} 


\section{Introduction}

Approximately 5.8 million Americans suffer from heart failure (HF) ${ }^{1}$ and it is the only major cardiovascular disease that is increasing in prevalence. ${ }^{2}$ Symptom instability and clinical deterioration frequently lead to hospitalization for the HF patient with associated annual direct and indirect costs in excess of $\$ 39$ billion. 1,3

Despite intensive medical therapy, HF symptoms including dyspnea, fatigue, and lower-limb swelling, are highly prevalent and burdensome, profoundly limiting daily activities and greatly diminishing quality of life $(\mathrm{QoL}){ }^{4}$ Depression also is very common in HF; a metaanalysis reported prevalence estimates ranging from $20.3 \%$ (when depression was classified by a clinical interview, a formal depression diagnosis, and/or a moderate to severe depression score on a depression symptom inventory) to $35.5 \%$ (when mild depression or depressive symptoms were evaluated by lower cutoff scores on validated questionnaires). ${ }^{5}$ Depression is associated with an increased risk of adverse outcomes for patients with established $\mathrm{HF}^{6}$ and although depression in $\mathrm{HF}$ patients is related to disease severity, the impact of depression on adverse clinical outcomes has been shown to be independent of $\mathrm{HF}$ disease biomarkers, including B-Type natriuretic peptide (BNP), left ventricle ejection fraction (LVEF), and other established risk factors. ${ }^{7}$ These findings underscore the need for intervention programs that may help reduce distress and depression and thereby improve both QoL and clinical outcomes in HF patients. ${ }^{8}$

Non-adherence to prescribed disease management therapies including medications, and dietary and fluid recommendations are contributing factors to hospital re-admissions. ${ }^{9-10}$ Several studies have demonstrated that HF disease management programs may prolong event-free survival, decrease the number of hospital admissions and improve QoL. ${ }^{11-13}$ Other effective interventions have included telemonitoring, incorporating electronic weighing scales and blood pressure monitors in addition to regular telephone calls. ${ }^{14-16}$ In addition, weekly monitoring calls have been shown to improve clinical outcomes, reduce hospitalizations and improve QoL. ${ }^{17-18}$ Because telephone-based interventions have been found to be both effective and inexpensive to deliver, there is a need to further develop and refine these approaches. ${ }^{19}$

Coping skills training (CST) is a cognitive-behavioral approach to disease self-management that retrains maladaptive coping styles into more constructive behaviors, facilitates compliance with medical treatment recommendations, and improves psychological wellbeing. ${ }^{20}$ Research studies evaluating the enhancement of established monitoring/education programs with behavioral treatment programs have shown that for other chronic diseases, including diabetes, coronary heart disease and end-stage lung disease, CST interventions enhance self-management and improve patient health and QoL. ${ }^{21-25}$ Because HF is a chronic disease that not only necessitates rigorous medical self-management, but in addition has a broad impact on both physical and psychological functioning, the CST approach to disease management has the potential to improve both health and well-being in HF patients (Figure 1). However, the CST approach to disease management has not been studied systematically in patients with HF.

Coping Effectively with Heart Failure (COPE-HF; www.clinicaltrials.gov NCT00873418) is a randomized clinical trial designed to evaluate the hypothesis that a CST intervention, tailored to address the unique challenges faced by patients with HF, will result in improved health status, QoL, and long-term clinical outcomes compared with a Heart Failure Education (HFE) intervention. Outcome measures include post-intervention improvements in: 1) HF disease severity biomarkers; 2) QoL and; 3) health outcomes (mortality or hospitalization) over a 3-year median follow-up period. Secondary objectives will assess the 
extent to which treatment-related changes in HF disease severity biomarkers and QoL are associated with long-term clinical outcomes and whether the behavioral pathways targeted by the CST intervention explain treatment-related improvements in health status and clinical outcomes.

\section{Methods}

\section{Participant Eligibility}

The COPE-HF trial will consist of $200 \mathrm{HF}$ out-patients recruited from the HF program clinics at Duke University Medical Center (DUMC) and the University of North Carolina (UNC) Hospital system. Eligibility criteria include men and women aged 18 or older; with New York Heart Association (NYHA) Class II-IV HF of at least 3-months duration; LVEF $\leq 40 \%$ by left ventricular angiography, nuclear wall motion study, or echocardiography, within 6 months of study enrolment; and undergoing treatment with a stable medication regimen. Exclusion criteria include acute myocardial infarction (AMI), percutaneous transluminal coronary angioplasty (PCTA), coronary artery bypass graft surgery (CABG), or hospitalization for HF within the past 3 months; HF due to a correctable cause or condition such as uncorrected primary valvular disease; alcohol or drug abuse within 12 months; illnesses such as malignancies that are associated with a life-expectancy of $<12$ months; pregnancy; psychosis; or inability to provide informed consent. There will be active recruitment of women and minorities, aiming for least $40 \%$ women and $30 \%$ minorities. We will document de-identified characteristics, (including gender, age, ethnicity, LVEF, BNP, NYHA class, creatinine) of eligible patients who choose not participate in the study. The protocol has been approved by the Institutional Review Boards at DUMC and the UNC School of Medicine. All eligible individuals will provide written informed consent prior to participation.

\section{Study Design}

COPE-HF is a randomized clinical trial in which 200 men and women with HF will be randomized in a 1:1 ratio to either Coping Skills Training (CST) or Heart Failure Education (HFE), after completing baseline assessments. A conditional randomization procedure (PROC PLAN in SAS 9.2) will be used to stratify participants on etiology of HF (ischemic versus non-ischemic) and age ( $<60$ years versus $\geq 60$ years). A schematic of the study design is displayed in Figure 2.

\section{Interventions}

Coping Skills Training (CST) Intervention-The CST interventionist will provide participants with 16 weekly, 30-minute phone calls. This approach will consist of cognitive behavioral techniques patterned after our previous studies of lung transplant ${ }^{21}$ and cardiac ${ }^{25-27}$ patients, with individually tailored cognitive-behavioral techniques to enhance coping skills, together with a motivational interviewing (MI) approach to enhance adherence to prescribed medical therapies. The central elements of the CST intervention will consist of: 1) education about HF, stress, and health;2) enhancing adherence to prescribed medical therapies (e.g., diet, physical activity, and medications; 3) reflective listening; 4) cognitive restructuring; 5) instruction in specific coping techniques (e.g., relaxation training, problemsolving, pacing of physical activity, calming self-statements); 6) change talk; and 7) maintenance and generalization.

Heart Failure Education (HFE) Intervention-Participants randomized to HFE will receive 16 weekly, 30 minute phone calls, from the HFE interventionist, providing information regarding HF health behaviors, including symptom monitoring, importance of daily weighing, compliance with medications, physical activity, and avoidance of dietary 
sodium. In addition to representing an education-based intervention, the HFE represents an intervention arm that controls for weekly telephone contact and provides an appropriate reference for evaluating the potential benefits of the CST intervention.

\section{Equipose}

Because the CST intervention includes components of the HFE intervention (HF disease education, symptom monitoring, compliance with medical recommendations) that have been shown to improve clinical outcomes, ${ }^{15}, 19$ we felt that adopting Usual Care as a control condition would not uphold the RCT principle of equipoise. The inclusion of HFE and CST interventions will achieve equipoise in that both arms of the RCT include elements of established efficacy. It is reasonable to expect that both interventions be perceived by patients as valuable extensions of their medical care.

The study is designed to evaluate the hypothesis that the unique aspects of CST (CBT, MI) will have a specific advantage for patients beyond that of the HFE intervention. Therefore, the HFE intervention will also provide a more rigorous and informative test of the value of CST, than would result from a Usual Care control group.

\section{Treatment Fidelity}

A number of steps will be taken to ensure that the treatment protocols are uniform and that interventionists follow the treatment protocols in a consistent manner. These include interventionist training, use of a detailed treatment outline, audio-taping of sessions and ongoing supervision, and assessments of treatment adherence and interventionist competence.

\section{Ongoing Medical Care}

All study participants in the DUMC and UNC HF program clinics will continue with their regular medical care. All patients will be followed by their cardiologists, in an ongoing fashion, who will manage any episodes of escalating symptoms or disease progression.

\section{Assessments of HF Biomarkers, Functional Status and Health Behaviors}

Participants will be assessed at baseline and again immediately following completion of the 16 week intervention, or after 6 months, whichever comes first. All assessors will be blinded to the intervention to which participants had been randomized.

Echocardiography-Two-dimensional images with harmonic imaging, pulsed and continuous wave Doppler tracings, color flow Doppler images, and tissue Doppler tracings will be obtained from standard parasternal and apical views. The following indices of left ventricular (LV) size and function and left atrial size will be measured: 1) LVEF will be determined using the biplane Simpson's rule from apical 4-chamber and 2-chamber images of the heart, ${ }^{28}$ 2) LV end-diastolic volume will be determined by the biplane Simpson's rule, as described above; ${ }^{28}$ 3) LV filling pressure will be derived from the ratio of early transmitral Doppler flow velocity to the early diastolic mitral annular velocity measured by tissue Doppler; ${ }^{29}$ 4) left atrial volume will be estimated by using the biplane area-length formula; ${ }^{28}$ and 5) mitral regurgitation severity will be quantified as the effective regurgitant orifice area using the PISA method. ${ }^{30}$

Blood Biomarkers-Following overnight fasting, blood will be collected from an antecubital vein. Samples will be placed on ice, cold-centrifuged at $1000 \mathrm{X} \mathrm{g}$ for $10 \mathrm{~min}$. The resulting plasma will be frozen and maintained at $-80^{\circ} \mathrm{C}$ until assay. B-type natriuretic peptide (BNP) measurements will be performed within 4 hours of thawing using an 
immunochemiluminometric assay (ICMA). Blood samples also will be used to determine high-sensitivity C-Reactive Protein (hsCRP; rate nephelometry), troponin I (ICMA), fasting lipids (automated enzymatic assay), creatinine (visible endpoint reflectance), hemoglobin and hematocrit (colorimetric and electronic impedance).

Brachial Artery Flow-mediated Dilation (FMD)—Impaired FMD has been shown to predict adverse clinical outcomes, including mortality in HF patients. ${ }^{31}$ Our technique $^{32}$ for assessing FMD follows procedures first described by Celermajer et al., ${ }^{33}$ and conforms to current standards established by committee guidelines published in $2002 .{ }^{34}$ Longitudinal Bmode ultrasound images of the brachial artery, $4-6 \mathrm{~cm}$ proximal to the antecubital crease, will be obtained using an Acuson Aspen (Mountain View, California) ultrasound platform with an $11 \mathrm{MHz}$ linear array transducer. All images will be obtained by the same sonographer (blinded to treatment) under the following conditions: 1) after 10 min of supine relaxation; 2) during reactive hyperemia, induced following inflation for 5-minutes to suprasystolic pressure $(200 \mathrm{mmHg}$ ) of a pneumatic occlusion cuff placed around the forearm. End-diastolic images will be stored and arterial diameters measured as the distance between the proximal and distal arterial wall intima-media interfaces using PC-based software (Brachial Analyzer - Version 5.0, Medical Imaging Applications LLC, Iowa City, Iowa). Peak FMD response will be assessed from 10-120 seconds post-deflation of the cuff, with peak arterial diameter quantified using polynomial curve fitting, and FMD defined as the maximum percent change in arterial diameter relative to resting baseline.

24-hour Heart Rate Variability (HRV)—Participants will be instrumented with a DelMar-Reynolds Holter ambulatory ECG recorder to wear for 24 hours while engaging in their normal pattern of activity. The Pathfinder three-channel ECG analyzer (DelMarReynolds Medical, Irvine, California, USA) will be used to scan the tapes using standard Holter analysis procedures. The labelled beat-to-beat file will then be processed using the DelMar HRV analysis software. HRV will be estimated from the standard deviation of all normal R-R intervals (SDNN).

24-hour Urinary Catecholamines and Electrolytes-Urine will be collected over a 24-hour period and kept cold by storage in a portable cooler. Samples will be assayed for norepinephrine, epinephrine (liquid chromatography/tandem mass spectrometry), sodium, potassium (flame photometry) and creatinine (kinetic).

6-Minute Walk-The primary measure of functional capacity will be the 6-minute walk test, performed per American Thoracic Society standards, ${ }^{35}$ at baseline and again postintervention.

Daily Physical Activity-Routine daily physical activity will be recorded in 1-minute epochs using an accelerometer (Actiwatch ${ }^{\circledR}-64$, Mini Mitter Co., Inc., Bend, Oregon) worn on the wrist of the non-dominant arm for 24-hours prior to randomization and again for 24hours immediately following post-intervention. In addition, participants will complete the Physical Activity Recall (PAR) self-report scale at baseline and post-intervention. ${ }^{36}$

Medication Adherence-The Medication Event Monitoring System (or MEMS®) bottle cap will be used to monitor medication adherence for 10 days at baseline and again for two weeks immediately post-intervention. The MEMs bottle cap registers each time the medication bottle cap is opened and closed. In addition, the Morisky Medication Adherence Scale (MMAS), ${ }^{37}$ a self-report scale of medication adherence, will be administered at baseline and post-intervention. 
Dietary Sodium Intake-Patients will complete a 24-hour standardized dietary recall with a nutritionist to assess nutrient composition and compliance with dietary recommendations. In addition, 24-hour urine sodium and potassium excretion will be determined by assaying an aliquot of a 24-hour urine sample, providing an objective measurement of sodium and potassium intake. ${ }^{38}$

Psychosocial Functioning and QoL-A battery of validated psychometric instruments will be completed at baseline and post-intervention to measure QoL (Medical Outcomes Survey, Short Form-36; SF-36 ${ }^{39}$, Kansas City Cardiomyopathy Questionnaire; KCCQ ${ }^{40}$ ), depression (Beck Depression Inventory; BDI-II ${ }^{41,42}$ ), anxiety (State-Trait Anxiety Inventory; STAI ${ }^{43}$ ), self-care of HF (Self-Care of Heart Failure Index; $\mathrm{SCHFI}^{44}$ ), stress (Perceived Stress Scale; PSS ${ }^{45}$ ), social support (Perceived Social Support Scale; PSSS ${ }^{46}$ ), coping (COPE Inventory ${ }^{47}$ ), and attitudes about impairment (Attitudes About Impairment instrument; $\left.\mathrm{AAI}^{48}\right)$.

\section{Statistical Analysis}

Treatment Effect on Primary Outcomes-The effect of treatment on HF disease severity biomarkers and QoL outcomes will be assessed immediately following the 16-week intervention using the global rank score procedure recommended by $\mathrm{O}^{\prime} \mathrm{Brien}^{49}$ for multiple endpoints. The O'Brien procedure was chosen because global procedures have been shown to be more powerful than corrected individual tests. ${ }^{49-51}$ The O'Brien procedure will be more powerful than individual tests with Bonferroni correction for which at least some endpoints will exhibit at least a moderate treatment effect in the expected direction, and no other endpoints will show a response in the unexpected direction (in contrast to where at least one endpoint needs to have a very strong treatment effect in the expected direction). ${ }^{51}$ The general approach is to combine the multiple endpoints into a global score for each domain of interest. Before combining them, the scales of the separate endpoints are made commensurate by transforming each score into ranks. For each endpoint, the entire sample will be rank ordered. For example, plasma BNP will be ranked in ascending order and LVEF, HRV and brachial artery FMD will be ranked in descending order. We will create separate global scores for HF disease severity biomarkers and QoL for each patient by averaging the ranks of their corresponding individual components. The global HF disease severity biomarkers score will be comprised of the following measures: plasma BNP, LVEF, HRV, and brachial artery FMD. The global QoL score will include the 6-minute walk, KCCQ, BDI-II, COPE, and AAI. Primary hypotheses will be tested by comparing the distributions of the residualized global scores in each group using the procedure described by Stokes et al. ${ }^{52}$ Secondary analyses will examine the individual endpoints (i.e., the components of the global scores) using a non-parametric analysis of covariance method. ${ }^{53}$ These analyses will offer an indication of whether particular components were especially responsive to the intervention.

Treatment Effect on Clinical Outcomes-Our proposed composite clinical endpoint is the time to death or first hospitalization (whichever occurs first) within a median period of 3 years from baseline assessments. Hospitalizations will be categorized as "cardiovascular" (including worsening HF, AMI, stroke, transient ischemic attack, heart transplant, valve replacement, CABG, angiogram/PCTA, arrhythmia, defibrillator and/or pacemaker implant, revascularization, amputation), "non-cardiovascular" (including major and minor surgeries, infectious diseases), and "emergency room" visits. Documentation of patient mortality will include verification through the acquisition of hospital and Emergency Medical Services records. Medical services records will be reviewed at semi-annual cause-of-death (COD) committee meetings, whereby COD will be established by consensus and categorized as sudden cardiac death, progressive heart failure, MI, stroke, TIA, or non-cardiovascular. 
Because of sample size limitations, the Cox proportional hazards model will be used to evaluate the effect of treatment on the composite endpoint of time to all-cause death or first all-cause hospitalization. However, for completeness, we also will perform and report parallel analyses focusing on time to death or first hospitalization due to cardiovascular causes. Participants who have not died or who have not been hospitalized during the study follow-up period will be considered censored cases, using time of last contact as the censoring time. The model will include the binary treatment indicator, along with age, gender, baseline medication adherence, BNP, LVEF, and HF etiology. In addition to examining the standard regression assumptions, assumptions specific to the Cox model will be assessed using techniques suggested by Schoenfeld. ${ }^{54}$ We will use Harrell's Design and Hmisc libraries ${ }^{55}$ in the R software package (http://cran.r-project.org) to conduct these analyses.

Power-With respect to the global HF severity and QoL scores, we estimated power assuming an attrition rate of about $20 \%$, multiple imputation for missing data, and two-sided tests. For the global rank outcomes, we define treatment effect size as the difference between the treatment and control groups divided by the pooled standard deviation. Given the relatively novel nature of the present study, little prior information is available regarding effect size estimates for the proposed treatment on these endpoints. Moreover, the practice of using prior data to estimate power has become controversial, with critics arguing that small pilot studies offer potentially misleading effect size estimates, making a poor basis for power estimation. ${ }^{56} \mathrm{We}$ take the view that a better approach to power estimation is to identify an effect size that would be considered clinically or substantively meaningful (see, for example, Lenth ${ }^{57}$ ). We identified an effect size of about a half-standard deviation as clinically meaningful for the global composite. Since the power for the composite is at least the magnitude of the corrected tests of the individual components, we examined whether a half standard deviation would be considered a substantively meaningful effect and also whether a change of this magnitude would be feasible. A .5 SD difference has been shown to be clinically meaningful for BNP, ${ }^{58-59} \mathrm{LVEF},{ }^{60} \mathrm{FMD},{ }^{61} \mathrm{BDI},{ }^{62}$ and the STAI. ${ }^{63} \mathrm{In}$ addition, a $.5 \mathrm{SD}$ effect has been shown to be feasible for BNP, ${ }^{64-65} \mathrm{FMD},{ }^{66-67} \mathrm{EF},{ }^{68} \mathrm{BDI}$, 64,69 and anxiety. ${ }^{70}$ For the test of a given global index, when alpha is .05 , for its proof-ofconcept, we estimate that 100 patients in each treatment arm will yield power of about .90 to detect a treatment effect size of about .50. Power for the Cox regression model was estimated assuming an event rate of $70 \%$ in the control group, 42 months for patient accrual, a median follow-up time of 36 months and a minimum follow-up time of 15 months. At alpha $=.05$, for its proof-of-concept, with 100 patients in each group we will have power of about .90 to detect a hazard ratio of 0.50 . For a global index or time to event that achieves proof-of-concept, a more stringent assessment will be made at an overall alpha $=.05$ through formal statistical significance at alpha $=.01$ for each of the two global indices, and alpha $=$. 03 for time to event.

\section{Conclusions}

Disease self-management is gaining increased recognition as a necessary adjunct to the medical treatment of chronic disease, and serves both to optimize patient health and contain health care expenditures. While approaches to disease self-management are typically educational, it has become evident that the provision of knowledge is insufficient by itself to change behavior. The CST intervention in COPE-HF employs state-of-the-art selfmanagement techniques to enhance adherence to medications and lifestyle behaviors (e.g., diet and physical activity), as well as to improve coping skills aimed at reducing distress and improving QoL. COPE-HF is a proof-of-concept randomized clinical trial comparing a telephone-based CST intervention with a HFE intervention. COPE-HF is designed to assess clinical efficacy in terms of hospitalization and mortality, and includes comprehensive pre- 
and post-treatment evaluations of HF biomarkers, functional status, and QoL measures, as well as recording health behaviors targeted by the interventions. In the context of existing knowledge, this design offers a prudent approach to evaluating optimal strategies for enhancing HF self-management.

\section{Acknowledgments}

This ongoing clinical trial is supported by Grant HL091920 from the National Heart, Lung, and Blood Institute, National Institutes of Health, Bethesda, MD, and grant M01-RR-30 from the General Clinical Research Center program, National Center for Research Resources, National Institutes of Health. We thank Dr. Ken Resnicow at the University of Michigan for his guidance in developing the motivational interviewing component of our Coping Skills Training intervention and Dr. Jacqueline Dunbar-Jacob for guidance in the assessment of medication adherence. We thank Dr. Gary Koch at the University of North Carolina School of Public Health for his guidance in study design and data analysis plan for this clinical trial. We are grateful to Dr. Mark Appelbaum at the University of California at San Diego, Dr. Stephanie Dunlap at the University of Cincinnati, and Dr. Judith McFetridge-Durdle at Memorial University of Newfoundland who have graciously agreed to serve on our Data and Safety Monitoring Board. We also wish to thank the anonymous reviewers of our NIH grant application whose input and support was invaluable to the success of our proposal.

\section{References}

1. Lloyd-Jones D, Adams RJ, Brown TM, Carnethon M, Dai S, De Simone G, et al. Heart disease and stroke statistics--2010 update: a report from the American Heart Association. Circulation. 2010; 121:e46-e215. [PubMed: 20019324]

2. Rosamond W, Flegal K, Friday G, Furie K, Go A, Greenlund K, et al. Heart disease and stroke statistics--2007 update: a report from the American Heart Association statistics committee and stroke statistics subcommittee. Circulation. 2007; 115:e69-171. [PubMed: 17194875]

3. Delgado-Passler P, McCaffrey R. The influences of postdischarge management by nurse practitioners on hospital readmission for heart failure. J Am Acad Nurse Pract. 2006; 18:154-60. [PubMed: 16573728]

4. Barnes S, Gott M, Payne S, Parker C, Seamark D, Gariballa S, et al. Prevalence of symptoms in a community-based sample of heart failure patients. J Pain Symptom Manage. 2006; 32:208-16. [PubMed: 16939845]

5. Rutledge T, Reis VA, Linke SE, Greenberg BH, Mills PJ. Depression in heart failure a metaanalytic review of prevalence, intervention effects, and associations with clinical outcomes. $\mathrm{J}$ Am Coll Cardiol. 2006; 48:1527-37. [PubMed: 17045884]

6. Albert NM, Fonarow GC, Abraham WT, Gheorghiade M, Greenberg BH, Nunez E, et al. Depression and clinical outcomes in heart failure: an OPTIMIZE-HF analysis. Am J Med. 2009; 122:366-73. [PubMed: 19332232]

7. Sherwood A, Blumenthal JA, Trivedi R, Johnson KS, O’Connor CM, Adams KF Jr, et al. Relationship of depression to death or hospitalization in patients with heart failure. Arch Intern Med. 2007; 167:367-73. [PubMed: 17325298]

8. de Leon CF, Grady KL, Eaton C, Rucker-Whitaker C, Janssen I, Calvin J, et al. Quality of life in a diverse population of patients with heart failure: baseline findings from the Heart Failure Adherence and Retention Trial (HART). J Cardiopulm Rehabil Prev. 2009; 29:171-8. [PubMed: 19471136]

9. Annema C, Luttik ML, Jaarsma T. Reasons for readmission in heart failure: perspectives of patients, caregivers, cardiologists, and heart failure nurses. Heart Lung. 2009; 38:427-34. [PubMed: 19755193]

10. Ambardekar AV, Fonarow GC, Hernandez AF, Pan W, Yancy CW, Krantz MJ. Characteristics and in-hospital outcomes for nonadherent patients with heart failure: findings from Get With The Guidelines-Heart Failure (GWTG-HF). Am Heart J. 2009; 158:644-52. [PubMed: 19781426]

11. Hebert KA, Horswell RL, Dy S, Key IJ Jr, Butler MK, Cerise FP, et al. Mortality benefit of a comprehensive heart failure disease management program in indigent patients. Am Heart J. 2006; 151:478-83. [PubMed: 16442918] 
12. Brotons C, Falces C, Alegre J, Ballarin E, Casanovas J, Cata T, et al. Randomized clinical trial of the effectiveness of a home-based intervention in patients with heart failure: the IC-DOM study. Rev Esp Cardiol. 2009; 62:400-8. [PubMed: 19401125]

13. Bocchi EA, Cruz F, Guimaraes G, Pinho Moreira LF, Issa VS, Ayub Ferreira SM, et al. Long-term prospective, randomized, controlled study using repetitive education at six-month intervals and monitoring for adherence in heart failure outpatients: the REMADHE trial. Circ Heart Fail. 2008; 1:115-24. [PubMed: 19808281]

14. Maric B, Kaan A, Ignaszewski A, Lear SA. A systematic review of telemonitoring technologies in heart failure. Eur J Heart Fail. 2009; 11:506-17. [PubMed: 19332417]

15. Clark RA, Inglis SC, McAlister FA, Cleland JG, Stewart S. Telemonitoring or structured telephone support programmes for patients with chronic heart failure: systematic review and meta-analysis. BMJ. 2007; 334:942.10.1136/bmj.39156.536968.55 [PubMed: 17426062]

16. Inglis SC, Clark RA, McAlister FA, Ball J, Lewinter C, Cullington D, et al. Structured telephone support or telemonitoring programmes for patients with chronic heart failure. Cochrane Database Syst Rev. 2010; 8:CD007228.10.1002/14651858.CD007228.pub2 [PubMed: 20687083]

17. Gregory D, Kimmelstiel C, Perry K, Parikh A, Konstam V, Konstam MA. Hospital cost effect of a heart failure disease management program: the Specialized Primary and Networked Care in Heart Failure (SPAN-CHF) trial. Am Heart J. 2006; 151:1013-8. [PubMed: 16644325]

18. Dunagan WC, Littenberg B, Ewald GA, Jones CA, Emery VB, Waterman BM, et al. Randomized trial of a nurse-administered, telephone-based disease management program for patients with heart failure. J Card Fail. 2005; 11:358-65. [PubMed: 15948086]

19. Chaudhry SI, Phillips CO, Stewart SS, Riegel B, Mattera JA, Jerant AF, et al. Telemonitoring for patients with chronic heart failure: a systematic review. J Card Fail. 2007; 13:56-62. [PubMed: 17339004]

20. Grey M, Berry D. Coping skills training and problem solving in diabetes. Curr Diab Rep. 2004; 4:126-31. [PubMed: 15035973]

21. Blumenthal JA, Babyak M, Carney RM, et al. Telephone-based coping skills training for patients awaiting lung transplantation. J Consult Clin Psychol. 2006; 74:535-544. [PubMed: 16822110]

22. Grey M, Boland EA, Davidson M, Yu C, Sullivan-Bolyai S, Tamborlane WV. Short-term effects of coping skills training as adjunct to intensive therapy in adolescents. Diabetes Care. 1998; 21:902-908. [PubMed: 9614605]

23. Grey M, Boland EA, Davidson M, Li J, Tamborlane WV. Coping skills training for youth with diabetes mellitus has long-lasting effects on metabolic control and quality of life. J Pediatr. 2000; 137:107-13. [PubMed: 10891831]

24. Lustman PJ, Griffith LS, Freedland KE, Kissel SS, Clouse RE. Cognitive behavior therapy for depression in type 2 diabetes mellitus. A randomized, controlled trial. Ann Intern Med. 1998; 129:613-21. [PubMed: 9786808]

25. Blumenthal JA, Jiang W, Babyak MA, Krantz DS, Frid DJ, Coleman RE, et al. Stress management and exercise training in cardiac patients with myocardial ischemia. Effects on prognosis and evaluation of mechanisms. Arch Intern Med. 1997; 157:2213-23. [PubMed: 9342998]

26. Berkman LF, Blumenthal J, Burg M, Carney RM, Catellier D, Cowan MJ, et al. Effects of treating depression and low perceived social support on clinical events after myocardial infarction: the Enhancing Recovery in Coronary Heart Disease Patients (ENRICHD) Randomized Trial. JAMA. 2003; 289:3106-16. [PubMed: 12813116]

27. Blumenthal JA, Sherwood A, Babyak MA, Watkins LL, Waugh R, Georgiades A, et al. Effects of exercise and stress management training on markers of cardiovascular risk in patients with ischemic heart disease: a randomized controlled trial. JAMA. 2005; 293:1626-34. [PubMed: 15811982]

28. Lang RM, Bierig M, Devereux RB, Flachskampf FA, Foster E, Pellikka PA, et al. Recommendations for chamber quantification: a report from the American Society of Echocardiography's Guidelines and Standards Committee and the Chamber Quantification Writing Group, developed in conjunction with the European Association of Echocardiography, a branch of the European Society of Cardiology. J Am Soc Echocardiogr. 2005; 18:1440-63. [PubMed: 16376782] 
29. Dokainish H, Zoghbi WA, Lakkis NM, Al-Bakshy F, Dhir M, Quinones MA, et al. Optimal noninvasive assessment of left ventricular filling pressures: a comparison of tissue doppler echocardiography and b-type natriuretic peptide in patients with pulmonary artery catheters. Circulation. 2004; 109:2432-9. [PubMed: 15123522]

30. Zoghbi WA, Enriquez-Sarano M, Foster E, Grayburn PA, Kraft CD, Levine RA, et al. Recommendations for evaluation of the severity of native valvular regurgitation with twodimensional and doppler echocardiography. J Am Soc Echocardiogr. 2003; 16:777-802. [PubMed: 12835667]

31. Katz SD, Hryniewicz K, Hriljac I, Balidemaj K, Dimayuga C, Hudaihed A, et al. Vascular endothelial dysfunction and mortality risk in patients with chronic heart failure. Circulation. 2005; 111:310-4. [PubMed: 15655134]

32. Sherwood A, Hinderliter AL, Watkins LL, Waugh RA, Blumenthal JA. Impaired endothelial function in coronary heart disease patients with depressive symptomatology. J Am Coll Cardiol. 2005; 46:656-9. [PubMed: 16098431]

33. Celermajer DS, Sorensen KE, Gooch VM, Spiegelhalter DJ, Miller OI, Sullivan ID, et al. Noninvasive detection of endothelial dysfunction in children and adults at risk of atherosclerosis. Lancet. 1992; 340:1111-1115. [PubMed: 1359209]

34. Corretti MC, Anderson TJ, Benjamin EJ, Celermajer D, Charbonneau F, Creager MA, et al. Guidelines for the ultrasound assessment of endothelial-dependent flow-mediated vasodilation of the brachial artery: a report of the International Brachial Artery Reactivity Task Force. J Am Coll Cardiol. 2002; 39:257-265. [PubMed: 11788217]

35. American Thoracic Society. ATS Statement: guidelines for the six-minute walk test. Am J Resoir Crit Care Med. 2002; 166:111-117.

36. Blair SN, Haskell WL, Ho P, Paffenbarger RS Jr, Vranizan KM, Farquhar JW, et al. Assessment of habitual physical activity by a seven-day recall in a community survey and controlled experiments. Am J Epidemiol. 1985; 122:794-804. [PubMed: 3876763]

37. Morisky DE, Green LW, Levine DM. Concurrent and predictive validity of a self-reported measure of medication adherence. Med Care. 1986; 24:67-74. [PubMed: 3945130]

38. Bentley B. A review of methods to measure dietary sodium intake. J Cardiovac Nurs. 2006; 21:637.

39. Ware JE, Sherbourne CD. The MOS 36-item short-form health survey (SF-36). I. conceptual framework and item selection. Med Care. 1992; 30:473-483. [PubMed: 1593914]

40. Green CP, Porter CB, Bresnahan DR, Spertus JA. Development and evaluation of the Kansas City Cardiomyopathy Questionnaire: a new health status measure for heart failure. J Am Coll Cardiol. 2000; 35:1245-55. [PubMed: 10758967]

41. Beck AT, Steer RA, Garbin MG. Psychometric properties of the Beck Depression Inventory: Twenty-five years of evaluation. Clin Psychol Rev. 1988; 8:77-100.

42. Martin A, Rief W, Klaiberg A, Braehler E. Validity of the Brief Patient Health Questionnaire Mood Scale (PHQ-9) in the general population. Gen Hosp Psychiatry. 2006; 28:71-7. [PubMed: 16377369]

43. Speilberger, CD. Manual for the State-Trait Anxiety Inventory (Form Y). Palo Alto, CA: Consulting Psychologists; 1983.

44. Riegel B, Carlson B, Moser DK, Sebern M, Hicks FD, Roland V. Psychometric testing of the selfcare of heart failure index. J Card Fail. 2004; 10:350-60. [PubMed: 15309704]

45. Cohen, S.; Williamson, G. Perceived stress in a probability sample of the US. Spacapam, S.; Oskamp, S., editors. Newbury Park, CA: Sage; 1988.

46. Zimet GD, Dahlem NW, Zimet SG, Farley GK. The multidimensional scale of perceived social support. Journal of Personality Assessment. 1988; 52(1):30-41.

47. Carver CS. Assessing coping strategies: a theoretically based approach. Journal of personality and social psychology. 1989; 56(2):267-283. [PubMed: 2926629]

48. Turvey CL, Klein DM, Pies CJ, Arndt S. Attitudes about impairment and depression in elders suffering from chronic heart failure. Int J Psychiatry Med. 2003; 33:117-32. [PubMed: 12968825]

49. O’Brien PC. Procedures for comparing samples with multiple endpoints. Biometrics. 1984; 40:1079-1087. [PubMed: 6534410] 
50. Tilley BC, Marler J, Geller NL, Lu M, Legler J, Brott T, et al. Use of a global test for multiple outcomes in stroke trials with application to the National Institute of Neurological Disorders and Stroke t-PA Stroke Trial. Stroke. 1996; 27:2136-42. [PubMed: 8898828]

51. Troendle JF, Legler JM. A comparison of one-sided methods to identify significant individual outcomes in a multiple outcome setting: stepwise tests or global tests with closed testing. Statistics in Medicine. 1998; 17:1245-60. [PubMed: 9670413]

52. Stokes, ME.; Davis, CS.; Koch, GG. Categorical data analysis using the SAS® System. 2. Cary, NC: SAS Publishing; 2000.

53. LaVange LM, Durham TA, Koch GG. Randomization-based nonparametric methods for the analysis of multicentre trials. Stat Methods Med Res. 2005; 14:281-301. [PubMed: 15969304]

54. Schoenfeld D. Partial residuals for the proportional hazards regression model. Biometrika. 1982; 69:239.

55. Harrell, FE. Regression modeling strategies. New York: Springer; 2001.

56. Kraemer HC, Mintz J, Noda A, Tinklenberg J, Yesavage JA. Caution regarding the use of pilot studies to guide power calculations for study proposals. Arch Gen Psychiatry. 2006; 63:484-9. [PubMed: 16651505]

57. Lenth RV. Some practical guidelines for effective sample size determination. Amer Statistician. 2001; 55:187-193.

58. Doust J, Lehman R, Glasziou P. The role of BNP testing in heart failure. Am Fam Physician. 2006; 74:1893-8. [PubMed: 17168346]

59. Doust JA, Pietrzak E, Dobson A, Glasziou P. How well does b-type natriuretic peptide predict death and cardiac events in patients with heart failure: systematic review. BMJ. 2005; 330:625. [PubMed: 15774989]

60. Curtis JP, Sokol SI, Wang Y, Rathore SS, Ko DT, Jadbabaie F, et al. The association of left ventricular ejection fraction, mortality, and cause of death in stable outpatients with heart failure. $\mathrm{J}$ Am Coll Cardiol. 2003; 42:736-42. [PubMed: 12932612]

61. Rossi R, Nuzzo A, Origliani G, Modena MG. Prognostic role of flow-mediated dilation and cardiac risk factors in post-menopausal women. J Am Coll Cardiol. 2008; 51:997-1002. [PubMed: 18325438]

62. Kendall PC, H SD, Beck AT, Hammen CL, Ingram RE. Issues and recommendations regarding use of the Beck Depression Inventory. Cognitive Ther Res. 1987; 11:289-299.

63. Ahern DK, Gorkin L, Anderson JL, Tierney C, Hallstrom A, Ewart C, et al. Biobehavioral variables and mortality or cardiac arrest in the Cardiac Arrhythmia Pilot Study (CAPS). Am J Cardiol. 1990; 66:59-62. [PubMed: 2193497]

64. Parissis JT, Papadopoulos C, Nikolaou M, Bistola V, Farmakis D, Paraskevaidis I, et al. Effects of levosimendan on quality of life and emotional stress in advanced heart failure patients. Cardiovasc Drugs Ther. 2007; 21:263-8. [PubMed: 17610056]

65. Karavidas A, Parissis J, Arapi S, Farmakis D, Korres D, Nikolaou M, et al. Effects of functional electrical stimulation on quality of life and emotional stress in patients with chronic heart failure secondary to ischaemic or idiopathic dilated cardiomyopathy: a randomised, placebo-controlled trial. Eur J Heart Fail. 2008; 10:709-13. [PubMed: 18558509]

66. Belardinelli R, Lacalaprice F, Ventrella C, Volpe L, Faccenda E. Waltz dancing in patients with chronic heart failure: new form of exercise training. Circ Heart Fail. 2008; 1:107-14. [PubMed: 19808280]

67. Parissis JT, Karavidas A, Bistola V, Arapi S, Paraskevaidis IA, Farmakis D, et al. Effects of levosimendan on flow-mediated vasodilation and soluble adhesion molecules in patients with advanced chronic heart failure. Atherosclerosis. 2008; 197:278-82. [PubMed: 17568589]

68. Wisloff U, Stoylen A, Loennechen JP, Bruvold M, Rognmo O, Haram PM, et al. Superior cardiovascular effect of aerobic interval training versus moderate continuous training in heart failure patients: a randomized study. Circulation. 2007; 115:3086-94. [PubMed: 17548726]

69. Karapolat H, Demir E, Bozkaya YT, Eyigor S, Nalbantgil S, Durmaz B, et al. Comparison of hospital-based versus home-based exercise training in patients with heart failure: effects on functional capacity, quality of life, psychological symptoms, and hemodynamic parameters. Clin Res Cardiol. 2009; 98:635-42. [PubMed: 19641843] 
70. Blumenthal JA, Babyak M, Moore KA, et al. Effects of exercise training on older patients with major depression. Arch Intern Med. 1999; 159:2349-2356. [PubMed: 10547175] 


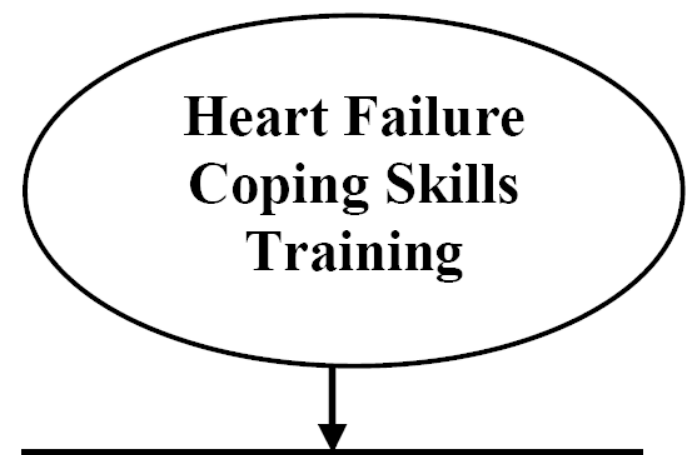

$\downarrow$ Distress

$\uparrow$ Medical Adherence

$\uparrow$ Health Behaviors

$\downarrow$ HF Biomarkers

$\uparrow$ Functional Status

$\uparrow$ QoL

\section{Event-free Survival}

Figure 1.

Conceptual model of coping skills training's effects on psychological well-being, improving health behaviors and heart failure (HF) disease, and promoting better clinical outcomes. QoL $=$ quality of life; $\uparrow=$ increasing; $\downarrow=$ reducing. 


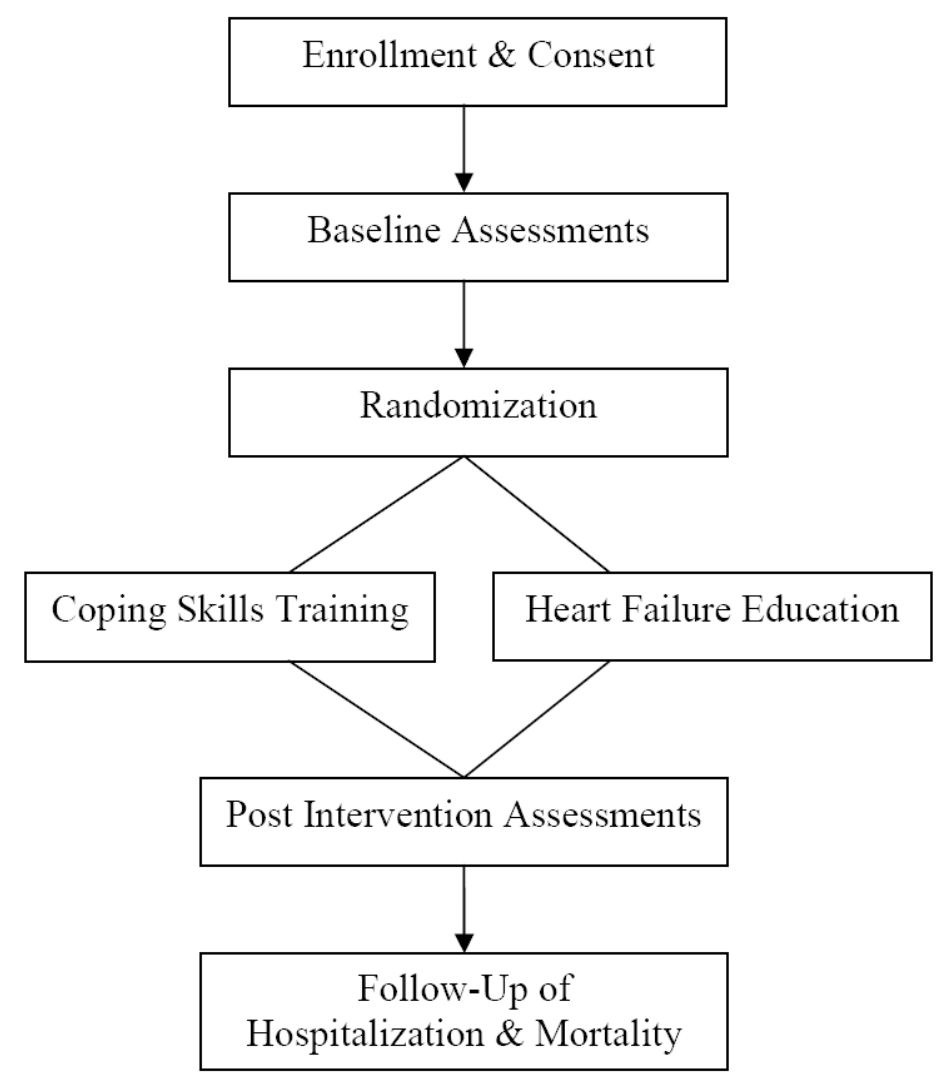

Figure 2.

Study Design Overview 